\title{
Investigation of dietetic interventions and outcomes for patients at risk of malnutrition in the community
}

\author{
S. Browne, S. Kennelly ${ }^{1}$, G. Flanagan-Rughaboor ${ }^{1}$ and C. Glennon-Slattery ${ }^{1}$ \\ ${ }^{1}$ Community Nutrition and Dietetics Service, Marlinstown Office Park, Mullingar, Co. Westmeath and ${ }^{2}$ Antogher Rd, \\ Roscommon, Co. Roscommon, Republic of Ireland
}

Best practice guidelines advocate the implementation of nutrition screening tools such as Malnutrition Universal Screening Tool ('MUST') by trained healthcare professionals in the community setting with onward referral to dietetic services for patients at risk of malnutrition (NICE, 2006). There is a lack of data available on the type of dietetic interventions used and on the effectiveness of the dietetic approach in the treatment of malnutrition in the community ${ }^{(1)}$. The aim of this study was to describe dietetic interventions used with patients at risk of malnutrition and to report body weight and body mass index (BMI kg.m ${ }^{-2}$ ) changes as outcomes of these interventions.

Ethical approval was granted by the research ethics committee of the Health Service Executive. A retrospective review of a random selection $(n=71 / 355)$ of dietetic record cards was carried out by an independent dietitian researcher for patients referred to the community dietetic service between 2006 and 2010. Information about the initial dietetic assessment and the most recent dietetic review of patients was recorded. Patients included had a MUST score of $\geq 1$, and were referred to the community dietetic service by healthcare professionals (general practitioners and nurses) who were trained to use MUST ${ }^{(2)}$.

There was a majority of female patients (56/71) compared to males (15/21) referred. The median age of patients was 79 years (IQR 37). The most common diagnoses were chronic obstructive airways disease (18\%), cerebro-vascular accident $(11 \%)$, dementia $(10 \%)$ and gastro-intestinal disorders $(8.5 \%)$. Eighty-five percent (60/71) of patients had a MUST score of 2 or more (high risk) and $66 \%$ had a BMI $\mathrm{kg} . \mathrm{m}^{-2}$ of less than $20 \mathrm{~kg} . \mathrm{m}^{-2}$ on referral to the dietetic service. The length of dietetic involvement with patients ranged from 28 to 1226 days (Median 184 days). There was a median of 4 dietetic contacts with each patient during the intervention period. Seventy-three percent $(52 / 71)$ of patients were reviewed by domiciliary visit on at lest one occasion. Body weight and BMI kg.m ${ }^{-2}$ at first and final dietetic assessment was available for $58 \%$ (34/56) patients. When deceased patients (15/71) were removed from the analysis, significant increases in body weight, and BMI kg.m ${ }^{-2}$ were seen between first and final dietetic assessments. Of this group 68\% (23/34) had an increase in body weight $(p<0.05)$ (median $+3.1 \mathrm{~kg})$ and $65 \%(22 / 34)$ had an increase in BMI $(p<0.01)\left(\right.$ median $\left.0.9 \mathrm{~kg} . \mathrm{m}^{-2}\right)$.

Table 1. Most frequently recorded dietetic interventions for patients at risk of malnutrition

\begin{tabular}{lc}
\hline Dietetic Intervention Recorded & $100 \%=71$ \\
\hline Patient advised to take additional high protein high energy snacks & $92 \%$ \\
Patient advised to fortify meals with additional energy and protein & $90 \%$ \\
Patient advised to eat three small meals and three snacks between meals (little and often) & $80 \%$ \\
Patient provided with written dietary advice e.g. meal plan & $80 \%$ \\
Patient advised to increase the number of meals eaten during the day & $62 \%$ \\
Patient advised to take oral nutritional supplement (ONS) products between meals & $77 \%$ \\
Patient advised increase energy intake by 500 kcals per day with specific recommendations & $62 \%$ \\
\hline
\end{tabular}

This study shows that the majority of patients referred to the community dietetic service by healthcare professionals who are trained to use MUST are at high risk of malnutrition and require multiple dietetic interventions. The findings suggest that dietetic interventions to treat patients at risk of malnutrition may contribute to increased body weight and body mass index. The data presented is observational but may inform future controlled studies to determine the effect of the dietetic intervention on treating malnutrition.

1. Stratton RJ, Green CJ \& Elia M (2003) Disease related malnutrition. Oxon UK: CAB International.

2. Kennelly S, Kennedy NP, Flanagan-Rughoobur G, Glennon-Slattery C and Sugrue S (2010) An evaluation of a community dietetics intervention on the management of malnutrition for healthcare professionals. Journal of Human Nutrition and Dietetics 23, 567-574. 